\title{
Text messages as a learning tool for midwives
}

\author{
D Woods, A Attwell, K Ross, G Theron
}

The use of cell phone text messaging to improve access to continuing healthcare education in under-resourced settings is not well documented. We aimed to assess whether this method of education is acceptable to South African midwives in both the public and private sectors. Essential healthcare lessons from the Maternal Care book of the Perinatal Education Programme (PEP) were delivered via text message to more than 2500 midwives each week for a period of 6 months. Each message concluded with a link to a website, where additional information about each lesson could be accessed. Results of a survey, conducted with 50 of the message recipients, demonstrated that the text messages were well received by the midwives; the information was widely shared with colleagues and was believed to improve learning and patient care. Lack of access to the Internet, or failure to utilise this facility to obtain additional information, indicated that limitations still exist in internet-based distance education, especially in the public sector. The use of text messaging promises to provide cost-effective learning opportunities, and improve a wide range of clinical services, such as the management of HIV-infected children and adults.

S Afr Med J 2012;102:100-101.
Perinatal Education Trust, Cape Town, South Africa D Woods, MD, FRCP, DCH

Electric Book Works, Cape Town, South Africa A Attwell, BA Hons, MA

Independent researcher

K Ross, BA, HDE

Department of Obstetrics and Gynaecology, Faculty of Health Sciences, Stellenbosch University, and Tygerberg Hospital, Cape Town, South Africa

G Theron, BSc Hons, MMed (O\&G), FCOG (SA)
Cell phones offer many potential learning opportunities for healthcare workers - in particular, midwives, who are vitally important in the management of pregnant women and their newborn infants. ${ }^{1}$ The use of cell phones to improve access to continuing education for midwives may help to address the need for ongoing training, especially in rural primary care facilities, that cannot be met by expensive, traditional methods of centralised, tutor-based training. This application could contribute to better care for all pregnant women, and therefore assist in lowering the unacceptably high mortality rate of mothers and their infants in South Africa.

Few publications exist for controlled trials of the use of text messaging to improve healthcare in under-resourced settings. ${ }^{2,3}$ In Kenya, personal text messages to healthcare workers over a period of 
Table I. Questions and answers from the telephone interviews of 50 midwives

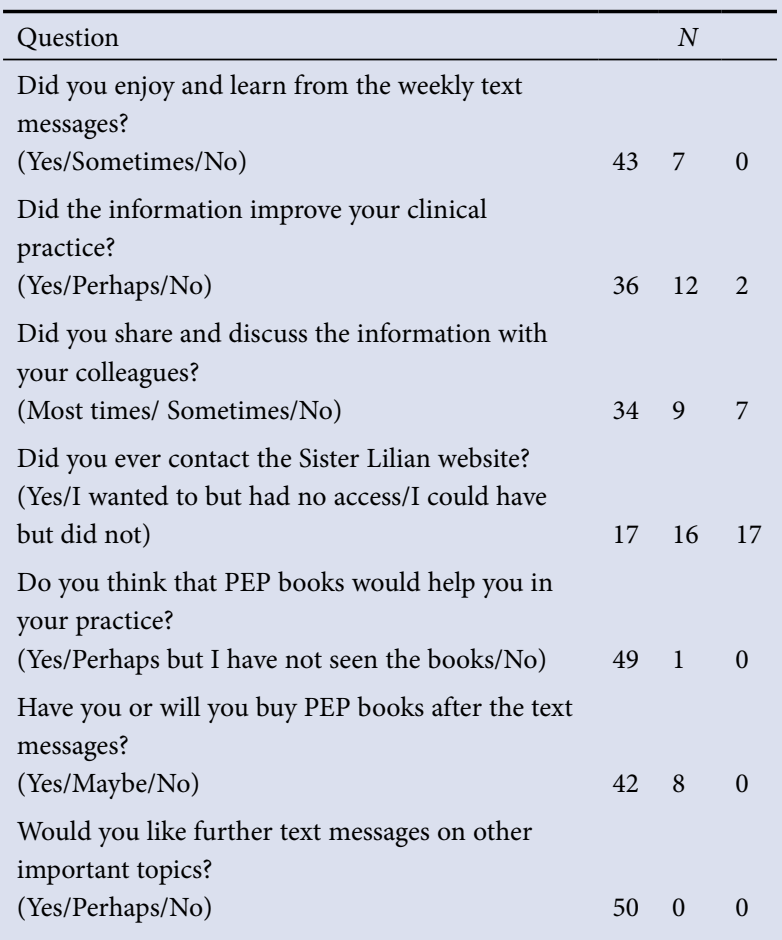

6 months significantly improved the management of children with malaria. ${ }^{4}$

A recent project has brought essential healthcare lessons from the Maternal Care book of the Perinatal Education Programme (PEP) to thousands of midwives through the medium of short message service (SMS) text messaging, using basic cell phones. The project aimed to assess whether this method of education is acceptable to midwives in the South African public and private sectors.

The PEP has been in force for 20 years to enable groups of midwives to take responsibility for their own continuing education. ${ }^{5}$ The effect of this inexpensive and accessible self-help learning method on their knowledge, clinical skills, attitudes and quality of care in South Africa, has been documented. ${ }^{6}$

\section{Methods}

The cell phone numbers of more than 2500 midwives were provided by the Sister Lilian Centre, which produces a quarterly nursing magazine, Sensitive Midwifery, and manages annual, popular and well-attended refresher courses for midwives. ${ }^{7}$ Twenty-six short, essential learning messages were selected from the Maternal Care course book of the PEP. Each message, limited to 160 characters, was sent via text message to the midwives every Tuesday over a 6-month period. Each message ended with a link to the Sister Lilian website, which in turn linked to the publisher's website, where the corresponding Maternal Care chapter could be read. ${ }^{8}$ Therefore, midwives with internet access could retrieve additional information relating to the core message. The cost of sending the text messages was reduced by purchasing large bundles of messages; during the study period, 70000 text messages were sent at a cost of 34 cents per message.
At the end of the project, 50 recipients were randomly identified: 25 in the public and private sectors, respectively. These midwives were contacted by an independent consultant, and asked to answer 7 short questions; each question had 3 possible answers ranging from positive to negative (Table I). Additional comments were recorded.

\section{Results}

All 50 recipients were willing to participate in the survey: $86 \%$ enjoyed and learned from the weekly text messages, $72 \%$ believed that the messages improved their clinical practice, and $68 \%$ regularly shared and discussed the messages with their colleagues. A total of $68 \%$ had access to the internet $(56 \%$ in the public and $80 \%$ in the private sector), but only half used the facility. Most (98\%) thought that the PEP books would help in their clinical practice, and $84 \%$ had already purchased the books or intended to do so. All respondents wanted to receive further text messages on other important topics.

Respondents' comments included: 'I loved the messages and learned a lot; the SMSs were a good reminder of things I already knew', 'I wrote the messages down so I could go back to them', 'I shared the messages with my students', 'I liked that they were short and quick to read', and 'Love the PEP books and use them. Some found that the messages were too simple and wanted more detailed information; consequently, links to the publisher's website were included in each message. Many looked forward to the weekly messages and asked to be included in future text message projects, as they wanted more information on a wide range of perinatal topics.

\section{Conclusions}

This survey demonstrated that text messages via personal cell phones were well received by South African midwives; the information was widely shared with colleagues and was believed to improve learning and patient care. The messages often formed the basis of discussions and student teaching. The lack of access to the Internet, and failure to use this facility to obtain additional information, indicated that internet-based distance education still has limitations, especially in the public sector.

A similar project is planned to provide essential messages on newborn care. We hope to determine whether weekly text messages could improve the standard of knowledge and practice of nurses in primary care facilities. The use of cell phone text messaging promises to provide cost-effective learning opportunities, and improve a wide range of clinical services, such as the management of HIV-infected children and adults.

\section{References}

1. Terry M. Text messaging in healthcare: the elephant knocking at the door. Telemed J E Health Terry M. Text messing

Lester RT, Ritvo P, Mills EJ et al. Effects of a mobile phone short message service on antiretroviral Lester RT, Ritvo P, Mills EJ et al. Effects of a mobile phone short message service on antiretrovira
treatment adherence in Kenya (WelTel Kenyal): a randomised trial. Lancet 2010;376(9755):1838-1845. 3. Pop-Eleches C, Thirumurthy H, Habyarimana JP et al. Mobile phone technologies improve adherence to antiretroviral treatment in a resource-limited setting; a randomized controlled trial of text message reminders. AIDS 2011;25(6):825-834.

4. Zurovac D, Sudoi RK, Akhwale WS et al. The effect of mobile phone text-message reminders on Kenyan health workers' adherence to malaria treatment guidelines: a cluster randomised trial. Lancet 2011;378(9793):795-803.

Woods DL, Greenfield DH. Teaching in under-resourced hospitals: experience in South Africa. NeoReviews 2010;11:5-11.

6. Perinatal Education Programme. www.pepcourse.co.za (accessed 11 October 2011).

7. The Sister Lilian Centre. www.sisterlilian.co.za (accessed 11 October 2011).

8. Electric Book Works Healthcare Series. www.ebwhealthcare.com (accessed 11 October 2011). 